\title{
Morcegos e o ensino de ciências: a percepção dos professores e a aplicação em sala de aula
}

\author{
Bats and science teaching: teacher perception \\ and classroom aplication
}

\author{
Crislaine Maria da Silva (crismariasilvacg@gmail.com) \\ Mestranda bolsista Capes do Programa de Pós-Graduação em Ensino das Ciências - PPGEC \\ Universidade Federal Rural de Pernambuco - UFRPE \\ Luiz Augustinho Menezes da Silva (luiz.augustinho@ufpe.br) \\ Docente Associado da Universidade Federal de Pernambuco - Centro Acadêmico de Vitória (UFPE- \\ CAV) \\ Docente do Programa de Mestrado Profissional em Ensino de Biologia (PROFIBIO-CAV)
}

Resumo: Os morcegos são mamíferos voadores envoltos em vários mitos, sendo o mais conhecido o vampirismo. Esta pesquisa busca identificar como o conteúdo morcegos é trabalhado e percebido pelos professores de Ciências em dois municípios pernambucanos. Foi aplicado um questionário com questões abertas aos professores que ensinam ciências na rede pública de ensino fundamental, quanto a sua formação, tempo de trabalho, sobre as notícias, os mitos, a importância dos morcegos, como os livros abordam o conteúdo sobre os quirópteros e como o assunto é trabalhado em sala de aula. Em seguida, foi realizada uma análise quali/quantitativa utilizando o método do Discurso do Sujeito Coletivo. A aplicação do questionário ocorreu com 31 professores, oito possuem mestrado e três estão no doutorado. Nas repostas, foram ressaltados pontos negativos relacionados aos morcegos e afirmam não ser comum trabalhar o tema nas escolas e as fontes de informação mais citadas foram (universidade, livros e documentários). Os professores usaram informações classificatórias, ecológicas, comportamental e o hábito para descreverem os morcegos. Em linhas gerais, esse estudo demonstrou a necessidade na abordagem de temas como esse em sala de aula, uma vez que os morcegos são cercados de mitos e em muitos casos tratados como sem importância e perseguidos pela população.

Palavras-chave: Percepção de professores; Morcegos; Ensino de Ciências.

Abstrat: The bats are flying mammals that are usually treated with lots of myths and the most known of them is the vampirism. This research quests to identify how the bats' content is managed and received by science teachers in two Pernambuco's cities. A quiz was applied to those teachers who educate in the public middle school (questions about their formation, how long they have worked, news, myths and importance of the bats, how the books broach about the chiroptera and how the content is studied in the classroom). After this, a qualitative/quantitative analysis was made by using the Collective Fellow Speech. The quiz was applied to 31 teachers ( 8 of them have a master degree and 3 of them are studying to get a doctor degree). In the answers, negative points related to the bats were highlighted and some of those teachers claim that it is not common to study this type of subject in the schools, the most quoted source of

Recebido em: $21 / 01 / 2020$

Aceito em: 08/07/2020 
information were university, books and documentaries. The teachers used classificatory, biological, behavioral information, and the habits to describe the bats. Thus, this research demonstrated the need in the approach of subjects like the bats in the classroom, once they are surrounded by myths, often treated like they have no significance and persecute by the population.

Keywords: Teachers' perception; Bats; Science instruction.

\section{INTRODUÇÃO}

No Brasil, diversos trabalhos foram realizados sobre a percepção acerca dos quirópteros, direcionados a diferentes públicos que incluíam comunidades escolares e universitárias, agricultores e moradores do entorno de parques, moradores de diversas cidades, entre outros (SCAVRONI; PALEARI; UIEDA, 2008; MARQUES; ORTENCIO FILHO; MAGALHÃES JUNIOR, 2011; SIMÕES et al., 2012; SILVA et al., 2013; DIAS et al., 2016). Percebe-se nos trabalhos que há uma exaltação de aspectos negativos, mitos e crendices pela população em geral que fazem com que os morcegos sejam percebidos como seres sem importância e que devem ser eliminados, subestimando assim os benefícios que eles podem fazer.

Vale salientar que, além da multiplicação de ideias errôneas como são considerados (vampiros e ratos que criaram asas), a mídia na maioria das vezes dissemina tal preconceito (CAPPARROS; MAGALHÃES JÚNIOR, 2015), e os livros didáticos de ciências e biologia abordam de forma superficial o conteúdo sobre os quirópteros, sendo insatisfatórias as informações contidas e algumas descontextualizadas (QUEIROZ; SILVA, 2015; BARREIRO; ORTÊNCIO FILHO, 2016). Sendo assim, estas informações são insuficientes para ajudar os estudantes a construírem uma concepção positiva sobre os morcegos.

Apesar de predominar uma percepção negativa sobre esses animais, como visto acima, em alguns países estes animais são sinônimos da sorte (GOMES; NETO, 2016) e os benefícios que os mesmos proporcionam aos diferentes ecossistemas onde ocorrem são incontestáveis (PACHECO et al., 2006; REIS et al., 2007; REIS et al 2017). Por isso, é importante conhecer as percepções que os integrantes da sociedade apresentam sobre os diversos atributos que compõem o ambiente, neste caso os morcegos (REIGOTA, 1991) para melhor direcionar as ações de conservação sobre as espécies e para descontruir conceitos errôneos.

Recebido em: $21 / 01 / 2020$

Aceito em: 08/07/2020 
Os quirópteros geralmente provocam medo e são considerados pouco carismáticos para população em geral, principalmente para crianças (SILVA et al., 2013). Vale ressaltar que todos os folclores, lendas e superstições contribuem para esse temor (PAIVA, 2010). Além disso, o mito de que o morcego é um ser maligno que se transforma em vampiro e bebe o sangue de humanos, ou que ele é um rato velho que criou asas é frequentemente disseminado, o que gera sérios problemas na relação do homem com o morcego (DRUMMOND, 2004). Sendo assim, em muitos casos os morcegos são eliminados pela população humana quando são encontrados, independente dos serviços ecossistêmicos que realizam.

Nesse entendimento, alguns fatores, como o hábito noturno e o fato de repousarem de cabeça para baixo contribuem para esse temor. Somam-se, ainda, todos os folclores, lendas e superstições envolvendo os morcegos. Uieda (2007) destaca ainda que os hematófagos são os grandes responsáveis por essa aversão, visto que a população leiga na maioria das vezes afirma que todos os quirópteros se alimentam de sangue. Entretanto, apenas três espécies neotropicais possuem esse hábito alimentar, são elas: o morcego-vampiro-comum (Desmodus rotundus (É. Geoffroy, 1810)), o morcegovampiro-de-asas-brancas (Diaemus youngii (Jentink, 1893)) e o morcego-vampiro-depernas-peludas (Diphylla ecaudata Spix, 1823) e estas estão restritas às Américas (VOIGHT; KINGSTON, 2016). Logo, aproveitamos para explicar que possuir o hábito hematófago não é indicativo de negatividade, mas um item alimentar comum a diversos animais, e o que influencia nesse estigma é a forma como esses animais são percebidos pela população.

Diferentemente do que muitas pessoas pensam, estes animais são muito importantes para o equilíbrio do ecossistema e, inclusive, para o bem-estar do ser humano (REIS et al., 2007; REIS et al., 2017). Eles pertencem à classe Mammalia e possuem características exclusivas que os incluem na ordem Chiroptera, que significa "mãos transformadas em asa". Suas asas são formadas por um braço, um antebraço e por dedos alongados que permitem a estes animais voarem. Algumas vezes, os morcegos utilizam as asas para auxiliarem a subir em árvores, casas e até mesmo cavernas (OLIVEIRA et al., 2018) e representam os únicos mamíferos realmente voadores. 
Além disso, os morcegos possuem uma visão adaptada para ver na escuridão e dependem da audição como sentido principal para sua orientação e localização de suas presas. Estes possuem um sistema de ecolocalização, e uma aprimorada capacidade biológica de detectar a posição e a distância de presas e objetos no ambiente por meio da emissão de ondas de ultrassom, que não são audíveis para os seres humanos (OLIVEIRA et al., 2018) tais características são curiosidades importantes a serem trabalhadas com os estudante pois aguçam a percepção dos alunos.

A partir desse entendimento, é relevante explicar que os morcegos realizam serviços ecossistêmicos, conhecidos também como serviços ambientais ou da natureza e são associados à qualidade de vida e bem-estar das sociedades. Os serviços ecossistêmicos são processos naturais, como os ciclos biogeoquímicos, e são indispensáveis a nossa sobrevivência, como da biodiversidade de forma geral. Entre os serviços ecossistêmicos que os morcegos desempenham estão: o consumo de insetos e o consequente controle de pragas; a dispersão de sementes, relacionada ao consumo de frutos; e a polinização, decorrente do hábito de consumo do néctar em flores de algumas espécies vegetais (OLIVEIRA et al., 2018).

Vale salientar que os morcegos representam uma rica parcela da fauna silvestre que ocorre nos ambientes urbanos e nas grandes cidades (PACHECO; MARQUES, 2006) e continuam realizando os serviços ambientais a exemplo da polinização e no controle de insetos pragas urbanas, mesmo assim sofrem com a perseguição e tem as suas populações eliminadas nas cidades. Para minimizar esse impacto, Pacheco e Marques (2006) destacam que as atividades educativas são de grande importância para que seja informada a real função dos morcegos ao meio ambiente, de forma que os cidadãos sejam sensibilizados a preservá-los.

Mediante ao exposto, esta pesquisa tem por objetivo identificar como o conteúdo morcegos é percebido e trabalhado pelos professores de Ciências a fim de subsidiar futuros planejamento para abordagens do conteúdo em sala.

\section{METODOLOGIA}

\section{Universo da pesquisa}

Esta pesquisa foi realizada no ano de 2018, em dois municípios de Pernambuco (Cumaru e Vitória de Santo Antão) e envolveu 18 escolas que contemplam o ensino 
fundamental (anos finais). Trinta e um professores que ensinam ciências na rede pública participaram da pesquisa e foram acessados após a autorização das Secretarias de Educação municipais e pela gestão escolar.

\section{Aplicação de questionários aos professores que ensinam Ciências}

Nessa pesquisa foi aplicado um questionário (Apêndice 1), composto por 19 questões. A maioria das questões foi aberta, algumas com a opção de (sim ou não), mas com o item: justifique sua resposta, aos professores que ensinam Ciências da rede pública de ensino fundamental (anos finais). O questionário levanta o perfil do professor e faz uma sondagem sobre os conhecimentos relacionados aos morcegos, o contexto do tema em sala de aula e como é realizada a abordagem do conteúdo em sala.

Segundo Oliveira (2016), a aplicação dos questionários implica na clareza que tem o pesquisador (a) quanto a necessidade de coletar dados que facilitem para a obtenção de informações que respondam aos objetivos propostos.

\section{Análise dos questionários}

Foi realizada uma análise quali/quantitativa, que proporciona uma maior credibilidade e validade aos resultados da pesquisa, o que evita o reducionismo por uma só opção de análise (OLIVEIRA, 2016).

Para análise dos dados foi utilizado o método do Discurso do Sujeito Coletivo (DSC) que se caracteriza pela reconstituição da representação social, conservando a sua dimensão individual articulada com a sua dimensão coletiva. Sendo assim, as opiniões e ideias individuais que exibem sentidos semelhantes são categorizadas. O DSC é uma forma metodológica de resgatar e apresentar as representações sociais obtidas de pesquisas empíricas. Nestas, as opiniões ou expressões individuais que apresentam sentidos semelhantes são agrupadas em categorias semânticas gerais, como normalmente se faz quando se trata de perguntas ou questões abertas (LEFEVRE; LEFEVRE, 2014). Com base nessa explicação da dimensão individual articulada a representação coletiva, o DSC foi escolhido para esta pesquisa, visto que foram 31 professores questionados.

Conforme os autores, o diferencial da metodologia do DSC é que a cada categoria estão associados os conteúdos das opiniões de sentido semelhante presentes em diferentes depoimentos, de modo a formar com tais conteúdos um depoimento 
síntese, redigido na primeira pessoa do singular, como se tratasse de uma coletividade falando na pessoa de um indivíduo.

\section{RESULTADOS E DISCUSSÃO}

\section{Perfil do professor}

A aplicação do questionário ocorreu com 31 professores, 22 são do sexo feminino e nove masculino. Em relação à formação dos professores, 26 são formados em Ciências Biológicas, cinco apresentam outra formação (Matemática, História, Geografia, Ciências Sociais e Física) e ensinam Ciências para completar a carga horária. Desses, 22 possuem especialização, oito possuem mestrado e três estão no doutorado. Todos os professores ensinam Ciências na rede pública, alguns deles ainda ensinam Matemática, Química, Biologia e Geografia. Todos atuam no ensino fundamental nos anos finais, alguns trabalham também no ensino médio, nos diferentes anos, em uma (21 professores), duas (7) ou três escolas (3). O tempo de docência variou de poucos meses a 30 anos. Com relação ao número de alunos atendidos anualmente pelos professores este variou de 150 a 500 alunos.

Sobre os recursos que são utilizados pelos professores em sala de aula ou para preparar as aulas foram citados principalmente o uso da internet (22 vezes), vídeos (oito vezes), data show (quatro vezes), revistas (três vezes), jornal e livro didáticos (duas vezes) e livros paradidáticos, artigos científicos e os parâmetros curriculares (uma vez).

\section{A Percepção dos Professores}

Os professores foram confrontados para citarem quatro palavras que vêm em sua mente ao falar sobre morcegos. Diante das respostas que surgiram destacaram-se mamíferos, medo, vampiro, sangue, noturno e raiva. Tais palavras puderam ser categorizadas de acordo com o significado que traziam (tabela 1). Apesar de aparecer categorias que abordam classificação, hábitos ou até mesmo importância, o destaque vai para mitos e afetividade onde a conceituação é negativa. Nesse sentido, vários são os trabalhos com outros grupos sociais que apresentaram concepções negativas acerca dos morcegos (NOVAES et al., 2008; MARQUES; ORTENCIO FILHO; MAGALHÃES JUNIOR, 2011; RIBEIRO; MAGALHÃES JUNIOR, 2015) observando assim, que a 
percepção negativa sobre estes animais circula por diferentes grupos tais como crianças, adolescentes, adultos, agricultores, estudantes dentre outros.

Tabela 1. Respostas apresentadas por professores de Ciências, acerca de palavras que vêm à mente ao pensar nos morcegos.

\begin{tabular}{|c|c|c|c|c|c|}
\hline Categoria & $\mathbf{N}^{\circ}$ de vezes & Concepção & Categoria & $\mathbf{N}^{\circ}$ de vezes & Concepção \\
\hline \multirow{3}{*}{ Classificação } & 4 & Animal & \multirow{9}{*}{ Afetividade } & 1 & Nojo \\
\hline & 1 & Mamíferos & & 6 & Medo \\
\hline & 1 & Quirópteros & & 3 & Pavor \\
\hline \multirow{4}{*}{$\begin{array}{l}\text { Hábitos e } \\
\text { habitat }\end{array}$} & 2 & Voadores & & 2 & Nojento \\
\hline & 7 & Noturno & & 1 & Cuidado \\
\hline & 3 & Cavernas & & 1 & Curiosidade \\
\hline & 2 & Escuro & & 1 & Mistério \\
\hline \multirow{3}{*}{ Importância } & 3 & Importância & & 1 & Abandono \\
\hline & 1 & Dispersores & & 1 & Distância \\
\hline & 4 & Asas & \multirow{3}{*}{ Estética } & 3 & Feio \\
\hline \multirow{8}{*}{ Mitos } & 5 & Vampiro & & 2 & Assustador \\
\hline & 2 & Rato com asas & & 2 & Horrível \\
\hline & 1 & Chupada & Características & 1 & $\begin{array}{l}\text { Caninos } \\
\text { (dentes) }\end{array}$ \\
\hline & 1 & Mordida & \multirow{3}{*}{ Dieta } & 1 & Sangue \\
\hline & 1 & Origem do rato & & 4 & Frutas \\
\hline & 1 & Batman & & 1 & Insetívoro \\
\hline & 1 & Mitos & \multirow[b]{2}{*}{ Zoonoses } & 8 & Raiva \\
\hline & 1 & Sugador de sangue & & 1 & $\begin{array}{c}\text { Vetor de } \\
\text { transmissão }\end{array}$ \\
\hline
\end{tabular}

Fonte: Elaborada pelo autor.

Com relação à pergunta sobre obtenção de informações sobre os morcegos, sete dos professores citaram que não receberam informações sobre estes animais, os demais professores afirmaram que já haviam recebido. Os professores indicaram diferentes fontes para estas informações (quadro 1), destacando - se a Universidade e os livros. Dentre as respostas algumas foram citadas apenas uma vez, revistas, congressos, hospital, palestras, casa e no consultório veterinário.

Dentre as notícias citadas pelos professores (quadro 2) destacaram-se reportagens de cunho negativo, os professores explicam que os morcegos atuam como vetores de doenças em animais e humanos e possuem algumas doenças associadas, como histoplasmose, e principalmente na transmissão da raiva, três dos participantes não responderam a essa questão. Entre as respostas da pergunta: Quais são as notícias que você lembra sobre morcegos? foi destacado o caso no sertão de Pernambuco (citado duas vezes), em Floresta de pessoas que morreram por terem se contaminado com o vírus da raiva, vinculado a transmissão pelos morcegos. Esse caso ocorreu em 2008 na cidade de Floresta e o adolescente sobreviveu, foi o terceiro caso no mundo (FOLHAPE, 2017).

Recebido em: $21 / 01 / 2020$

Aceito em: 08/07/2020 
Quadro 1. Respostas apresentadas por professores que ministram a disciplina de Ciências, nível fundamental, sobre o modo como obteve informações sobre os quirópteros.

\begin{tabular}{|c|c|c|c|}
\hline Fontes de consultas & Quantidade de vezes & Fontes de consultas & Quantidade de vezes \\
\hline Universidade & 6 & Internet & 3 \\
\hline Livros & 6 & Televisão & 3 \\
\hline Documentários & 5 & Artigos científicos & 2 \\
\hline Jornais & 4 & Exposição de anatomia & 2 \\
\hline Escola & 4 & Reportagens & 2 \\
\hline
\end{tabular}

Fonte: Elaborada pelo autor

Tais notícias, quando não divulgadas com cuidado influenciam na visão que o público tem sobre os morcegos, uma vez que a percepção negativa pode ser influenciada pela mídia (representada aqui pelos principais meios de comunicação - tv, jornais, revistas e internet) que exerce grande influência sobre a opinião, a percepção e as atitudes das pessoas, ao exaltarem os morcegos como aspectos negativos (CAPPARROS; MAGALHÃES JUNIOR, 2015).

Quadro 2. Respostas apresentadas por professores que ministram a disciplina de Ciências, nível fundamental, acerca das notícias quem os professores lembram sobre os morcegos.

\begin{tabular}{|c|c|c|}
\hline Descrição & Negativo & Positivo \\
\hline $\begin{array}{l}\text { Morcegos como vetores de transmissão - ou os fungos que ocorrem nas } \\
\text { fezes, ou ainda nos hematófagos que atacam bovinos. }\end{array}$ & 01 & \\
\hline O mito de que se alimentam de sangue & 01 & \\
\hline Que podem transmitir raiva. & 16 & 2 \\
\hline Caso do rapaz que contraiu raiva no sertão pernambucano. & 01 & S \\
\hline $\begin{array}{l}\text { Que os morcegos são responsáveis para manter o equilíbrio natural da } \\
\text { sua espécie e das demais. }\end{array}$ & & 01 \\
\hline QV//S São importantes para a permanência de outras espécies. & & 01 \\
\hline $\begin{array}{l}\text { Reportagens, sobretudo como a utilização deles para a natureza e } \\
\text { doenças vinculadas. }\end{array}$ & & 01 \\
\hline Homem é morto após ataque de morcego. & 01 & \\
\hline Doenças e importância no reflorestamento & & 01 \\
\hline $\begin{array}{c}\text { Uma pessoa próxima ao meu bairro morreu de raiva humana através das } \\
\text { investigações descobriu-se que um morcego mordeu um cachorro que } \\
\text { mordeu a senhora que faleceu. }\end{array}$ & 01 & \\
\hline Caso de raiva do menino em Floresta. & 01 & \\
\hline $\begin{array}{c}\text { Vigilância Ambiental encontra morcegos contaminados com Raiva em } \\
\text { Botucatu. }\end{array}$ & 01 & \\
\hline Um texto: vida na caverna, em um livro didático. & & 01 \\
\hline Menino contrai raiva após mordida de morcego no sertão. & 01 & \\
\hline
\end{tabular}

Fonte: Elaborada pelo autor

Distintos conceitos foram usados pelos professores para definir os morcegos. Estes usaram informações classificatórias como (animal, mamífero), ecológica (dieta), comportamental (voa) e de hábito (noturno). No geral, os morcegos foram descritos como sendo os únicos mamíferos que voam e de hábito noturno. 
É pertinente mencionar que os morcegos pertencem à Ordem Chiroptera, são os mamíferos mais diversos do mundo e possuem a segunda maior riqueza entre os mamíferos brasileiros, sendo superados apenas pela Ordem Rodentia (REIS et al., 2007; REIS et al., 2017). E ainda que, representam uma fauna rica e diversificada no ambiente urbano, e estes possuem uma ótima adaptação para esse meio antrópico, que oferece uma infinidade de abrigos e alimento (SOARES et al., 2011).

Os morcegos utilizam diferentes estruturas como abrigo, que podem ter origem antrópica (telhados, casas), vegetais (troncos, copas de árvores, folhagens, rochas, cavernas, fendas, frestas, furnas) em rochas (cavernas, furnas, fendas) ou, alguns utilizam também tocas de animais (LIMA, 2008; PACHECO et al., 2010; VILAR et al., 2016). Foram citados pelos professores, tanto abrigos artificiais como os naturais (quadro 03), destacando-se (casas abandonadas como artificial e cavernas como natural). Porventura é importante constar que locais escuros (ambientes úmidos e locais sombrios) apareceram 17 vezes. Apesar desses abrigos mais destacados serem utilizados pelos morcegos, o seu destaque pelos professores pode estar relacionado a influência da mídia, uma vez que tais abrigos são amplamente divulgados em filmes, documentários e historinhas.

Quadro 3. Respostas apresentadas por professores de Ciências, nível fundamental, acerca dos abrigos que os morcegos vivem.

\begin{tabular}{|l|l|}
\hline \multicolumn{1}{|c|}{ Categoria } & \multicolumn{1}{c|}{ Abrigos } \\
\hline Artificial & $\begin{array}{l}\text { Casas abandonadas (04), telhados de casas (03), sótão (03), quartos de estocagem } \\
\text { de alimento (01), forros de residência (01), áreas urbanas (1), igreja (01), porões } \\
(02) .\end{array}$ \\
\hline Natural & Cavernas (22), árvores (05), matas (03), florestas (02), grutas (01), toca (01). \\
\hline
\end{tabular}

Fonte: Elaborada por autor

A maior parte dos professores (23) conhecia os mitos e lendas associados aos morcegos, tais como o vampirismo, a lenda do conde Drácula, a sua origem a partir de ratos velhos, que são cegos e que suas fezes e urina cegam. Tais mitos têm multiplicidade a partir da mídia como o Vampirismo - As lendas sobre os vampiros são muito antigas e, com o auxílio da mitologia têm sido difundidas pelos povos. Com relação à associação ao vampirismo, temos que no século XV nasceu na Romênia o conde Vlad Drácula, ele foi príncipe e em seguida rei da região em que nasceu e cometeu diversas atrocidades com inimigos: arrancava suas peles, deixava-os a beira da morte e então bebia o sangue deles. A partir da história do Conde Drácula os contos 
sobre vampiros ganharam ascensão e logo foram associados aos morcegos, já que alguns destes apresentam dieta hematófaga (CONZO JUNIOR, 2014).

Relacionados a conceitos impregnados na população e que foram multiplicados de geração a geração, provavelmente associados a aspectos morfológicos dos animais, a exemplo Da Origem - Até o próprio nome morcego, derivado do latim muris (rato) e coecus (cego), contribui para aumentar a confusão, pois remete a maioria das pessoas a figura de um rato alado, noturno e sugador de sangue (REIS et al., 2007).

Os professores foram questionados sobre sua opinião sobre os mitos citados, seis professores não responderam. Os demais desacreditam dos mitos, mas afirmam que estes surgiram devido à influência da mídia em associação aos morcegos hematófagos e que tais mitos podem trazer problemas para a conservação dos morcegos e que as pessoas devem ser esclarecidas sobre a real importância destes animais. Alguns mencionaram o fato de que em algum momento de sua vida (infância e adolescência) acreditavam nos mitos relatados. Pode-se destacar como uma percepção geral de que os mitos estão principalmente vinculados aos morcegos hematófagos ou que as lendas são associadas a fantasias criadas pelos humanos, excluindo a real importância sobre esses animais (SIMÕES et al., 2012; SILVA et al., 2013).

Com relação à pergunta se os morcegos fazem parte da fauna urbana, dois professores negam essa associação, como citado por um deles "Que com a chegada dos humanos no ambiente natural e sua influência. Os morcegos começam a invadir a área urbana, porém estes animais não fazem parte da fauna urbana”. É perceptível que com a grande devastação do ambiente natural, com a presença de alimentos e abrigos artificiais nas cidades, estes acabam se adaptando. Estes são encontrados em casas, igrejas, assim fazendo parte da fauna urbana (VILAR et al., 2016).

Apesar dos professores afirmarem que os morcegos não fazem parte da fauna urbana. Vale destacar que algumas espécies animais utilizam o ambiente urbano como habitat, dentre elas muitas espécies de morcegos. li eles encontram alimento e abrigo bem como um número menor de predadores. $\mathrm{O}$ ambiente urbano quando mal planejados permitem o aparecimento de morcegos em especial de hábitos insetívoros e frugívoros (PACHECO et al., 2010), utilizam construções como abrigos e alimentam-se dos insetos atraídos pela iluminação pública, dos frutos e flores providos pelas árvores nas vias públicas e nos quintais das casas (BRASIL, 1998).

Recebido em: $21 / 01 / 2020$

Aceito em: 08/07/2020 
Em relação aos pontos positivos sobre os morcegos, a maioria dos entrevistados percebe que esses animais têm uma importância ecológica (quadro 4). Ter essa percepção é importante para a preservação dos morcegos. A relevância desse grupo de animais, para um melhor funcionamento ambiental, é inegável e deve ser disseminada da melhor maneira possível. Com a dieta evidentemente variada, os morcegos desempenham funções muito importantes na natureza, pois os estudos evidenciam os morcegos como grandes contribuidores na polinização e dispersão das sementes de diversas plantas no caso dos fitófagos e frugívoros, os insetívoros como controladores da população de insetos (LIMA, 1994; UIEDA, 2001).

Quadro 4. Respostas apresentadas por professores de Ciências, nível fundamental, acerca da importância dos morcegos.

\begin{tabular}{|c|c|}
\hline Ideia central & Discurso do sujeito coletivo (DSC) \\
\hline $\begin{array}{l}\text { Importância } \\
\text { ecológica }\end{array}$ & $\begin{array}{l}\text { Os morcegos exercem várias funções ecológicas, entre elas pode-se destacar que } \\
\text { atuam como polinizadores, auxiliando na reprodução de algumas plantas, são } \\
\text { controladores de insetos e de pequenos vertebrados. Atuam na dispersão de } \\
\text { sementes e auxiliam na manutenção da vida nas cavernas. Suas fezes servem de } \\
\text { alimento para os animais que vivem associados a cavernas. }\end{array}$ \\
\hline
\end{tabular}

Fonte: Elaborada pelo autor

Com relação aos pontos negativos sobre os morcegos, seis dos professores não souberam informar, os demais afirmaram que sim, que podem transmitir a raiva $(14$ vezes) ou que são vetores de doenças ( 9 vezes). Vale salientar que a maior associação é para o vírus da raiva que tem os morcegos como um dos vetores. É notório a relação com a transmissão de doenças vinculadas aos morcegos (SILVA, 2004).

Com relação aos hábitos alimentares citados pelos professores estes indicaram diferentes itens consumidos (quadro5) como frutos, sangue, insetos, pequenos vertebrados e sementes. Houve um destaque para frutos, sangue e insetos. Mesmo havendo um número pequeno de espécies com hábitos alimentares hematófagos (apenas 3 espécies) esse é um hábito muito difundido no conhecimento popular. Além desses pode-se citar os que apareceram apenas uma vez como, flores, folhas, pólen e pequenos animais.

Quadro 5. Respostas apresentadas por professores de Ciências, nível fundamental, acerca do que os morcegos comem.

\begin{tabular}{|c|c|}
\hline Recurso alimentar & Quantidade de vezes \\
\hline Frutas & 23 \\
\hline Sangue & 20 \\
\hline Insetos & 16 \\
\hline
\end{tabular}

Recebido em: $21 / 01 / 2020$

Aceito em: 08/07/2020 


\begin{tabular}{|c|c|}
\hline Néctar & 13 \\
\hline Peixe & 4 \\
\hline Anfíbios & 3 \\
\hline Sementes & 2 \\
\hline Ratos & 2 \\
\hline Lagartos & 2 \\
\hline Pássaros & 2 \\
\hline
\end{tabular}

Fonte: Elaborada por autor

Já quando direcionamos a pergunta com relação à riqueza mundial, nacional, estadual e municipal dos morcegos. Verificou-se que os professores apresentam total desconhecimento sobre estas riquezas, a maior parte das respostas estava nitidamente sub ou superestimadas, como pode ser visualizada na (tabela 2). No mundo existem cerca de 1.400 espécies de morcegos catalogadas (SIMMONS; CIRRANELLO, 2018), sendo descritas para o Brasil 181 espécies. Destas 82 para o estado de Pernambuco (REIS et al., 2017). A nível municipal não existem trabalhos que compuseram essa lista, mas a riqueza deve ficar próxima de 30 espécies

Tabela 2. Quantidade de espécies de morcegos citados pelos professores.

\begin{tabular}{cccc} 
Nível & Mínimo & Máximo & Media \\
Mundial & 5 & 100.000 .000 & 3.127 .376 \\
Nacional & 2 & 800.000 & 25.986 \\
Estadual & 1 & 100.000 & 3.560 \\
Municipal & 1 & 50.000 & 1.635 \\
\hline Fonte: Elaborada por autor & & &
\end{tabular}

Os professores reconheceram a ocorrência das espécies de hematófagos em dois ambientes (rural e cidades), entretanto alguns deles ampliam a distribuição para fora da América latina (quadro 6), e desconhecem o endemismo dos hematófagos para esta região.

Quadro 6. Respostas apresentadas por professores de Ciências, nível fundamental, acerca de onde os morcegos hematófagos vivem e sua distribuição.

\begin{tabular}{|c|c|}
\hline Categoria & Respostas \\
\hline Habitat & $\begin{array}{c}\text { Matas, locais que não tem disponibilidade de frutas, plantas e sementes, } \\
\text { locais escondidos, cavernas e florestas. }\end{array}$ \\
\hline Distribuição & $\begin{array}{c}\text { Nos trópicos, no Brasil, no México, Chile, América do Sul e Central, } \\
\text { África, Ásia e Oceania. }\end{array}$ \\
\hline
\end{tabular}

Fonte: Elaborada por autor

\section{Trabalhando com morcegos em sala}

Apenas um professor não considera importante trabalhar o tema nas escolas. Os demais destacaram essa importância e relacionam aos aspectos ecológicos, seus nichos, a importância para o meio ambiente e informam ainda ser relevante, desmistificar os Recebido em: $21 / 01 / 2020$ 
mitos, sensibilizar os estudantes e explicar que estes animais são protegidos. Essas ideias circundam a percepção que a população tem sobre estes animas, evidenciando assim, a relevância em trabalhar o conteúdo morcegos.

Treze dos professores afirmaram que este conteúdo não é abordado nos livros didáticos de Ciências. Para os professores que afirmaram que abordam o tema, estes citaram que o conteúdo morcegos aparece dentro das relações ecológicas, raiva, polinização, cadeia alimentar, hematófagos, taxonomia e principalmente dentro da classificação como mamíferos.

Sobre o questionamento em quais livros os morcegos são abordados, os docentes citaram que o conteúdo morcegos aparece principalmente em livros de Ciências do $7^{\circ}$ ano, como exemplo ao tratar da ordem dos quirópteros na classificação dos mamíferos. Já para o $6^{\circ}$ ano, afirmaram está associado ao conteúdo de ecologia - cadeia alimentar. Remetendo-se a esse conteúdo Barreiro e Ortêncio Filho (2016), já afirmam em seu trabalho a presença de 13 obras do $\left(6^{\circ}\right.$ ao $9^{\circ}$ ano $)$, com análise do livro didático.

Foi possível observar que parte dos professores não trabalha este conteúdo em sala (12 professores), apesar de terem mencionado que o conteúdo é importante de ser trabalhado. Tais direcionamentos nos fazem refletir e concordar com Tardiello e Robaina (2020), quando afirmam que é dever dos professores buscar alternativas para que o estudante compreenda a importância de estudar e consiga transpor aos muros da escola os conhecimentos construídos. Vale ressaltar, que esta pesquisa é vinculada a um projeto de extensão "Morcegos vão à escola: Conhecendo melhor os morcegos e outros animais" e parte das escolas foi contemplada com intervenções após a realização desse trabalho (exposições apresentações com fantoches, palestras) entre outros. E os professores junto à comunidade escolar começaram a ter acesso a informações.

Os assuntos pelos professores participantes da pesquisa, que são abordados são relacionados à classificação (mamíferos), participação na ecologia (dispersores de sementes, polinizadores), cadeia alimentar, ecossistemas, biomas e ecolocalização.

Muitas informações acerca dos quirópteros não são vistas em sala durante as aulas de Ciências/Biologia e questões importantes acabam não sendo elucidadas (PINHEIRO et al., 2018). É de fundamental importância que a formação de professores possibilite uma análise para melhor compreender as limitações presentes nos livros 
didáticos. Assim, se faz necessária a aplicação de práticas pedagógicas para subsidiar o conteúdo a ser ministrado (SARTIN et al., 2012). Diversas pesquisas endossam tais fatos e apontam a falta de contextualização com a realidade do cotidiano dos estudantes (FERREIRA; SELLES, 2004; BATISTA et al., 2010).

É notório que os docentes devem ter um cuidado em relação às informações que são ditas em sala de aula, especialmente com conteúdos que são mal compreendidos pela população, a exemplo dos morcegos. Dessa forma, é possível enfatizar sobre o questionamento sobre a realização de possíveis atividades práticas, os professores sugeriram principalmente, observação da anatomia dos morcegos, produção de maquetes, visita a museus, estudos em grupos, exposições, amostras científicas, visitar laboratórios que trabalhem com esses animais, morcegos de materiais recicláveis e elaboração de jogos. Logo, é primordial que a formação inicial dos docentes não se limite apenas à transmissão de informações, mas que busque formar um profissional que reflita sua prática, a ciência e a sociedade (SARTIN et al., 2012).

Sobre o questionamento aos professores, se eles identificavam interesse dos estudantes acerca do tema morcegos, treze dos professores não percebem interesse deles. Alguns dos professores disseram que os alunos ficam curiosos, outros que têm medo ou que ressaltam os aspectos negativos relacionados aos morcegos.

Nesse sentido, o trabalho de Silva et al. (2013) que constataram que crianças do ensino fundamental estão sempre associando os morcegos a uma série de mitos como: são venenosos, transformam-se em vampiros, transformam pessoas em zumbis, que matam as árvores, que todos transmitem raiva e que sua urina pode transmitir doenças. Poucas delas conheciam alguma característica, como o fato de que os morcegos são mamíferos e que possuem pelos. O primeiro passo na busca por novas relações entre alunos e morcegos é dar oportunidade para os estudantes expressarem suas ideias sobre tais animais, pois assim poderemos compreendê-las e delinear os próximos passos (LIMA; AVANZI, 2018).

Sobre a repulsa ou medo dos estudantes, a maioria dos professores afirma que os alunos têm repulsa dos morcegos e para amenizar, estes explicam sobre sua importância, aspectos positivos tentando desmitificar, diminuindo o medo que os estudantes possuem. Já em relação ao repulso ou medo dos morcegos por parte dos professores, os que responderam que não tem medo (14 professores), estes explicaram 
que sabem que não são perigosos e que são importantes para o ecossistema. No entanto, os docentes que responderam que tem repulsa, só ressaltam aspectos negativos acerca dos quirópteros.

Corroborando com este aspecto citado, várias pesquisas sobre percepção dos morcegos foram realizadas com crianças em escolas (SCAVRONI; PALEARI; UIEDA, 2008; SIMÕES et al., 2012; SILVA et al., 2013), adolescentes (SILVA; GENTILI, 2014) ou população em geral (NOVAES et al., 2008; MARQUES; ORTENCIO FILHO; MAGALHÃES JUNIOR, 2011; RIBEIRO; MAGALHÃES JUNIOR, 2015), e estes afirmam principalmente uma percepção que exalta pontos negativos acerca desses animais como mostra a percepção dos professores envolvidos na pesquisa.

\section{CONSIDERAÇÕES FINAIS}

Os morcegos são animais de extrema importância. No entanto, estes estão cercados de variados mitos, estereótipos e lendas que minimizam a sua importância e exaltam os aspectos negativos. Assim, se faz necessário ressaltar seus pontos positivos e sua importância ecológica. Neste trabalho foi possível observar que a concepção dos professores esteve voltada para muitos aspectos negativos, além da pouca contextualização desse conteúdo em sala de aula, mesmo sabendo da relevância do mesmo para o aprendizado crítico dos estudantes, auxiliando nas etapas da educação científica sendo importante a divulgação desse conhecimento entre os professores, incluído também outros grupos taxonômicos que sejam principalmente percebidos com negatividade.

É relevante constar que os professores em conjunto com a escola devem expandir o acesso às informações e realizar atividades abertas à comunidade leiga, como palestras, seminários, visitas ao ar livre e oficinas voltadas à divulgação científica, de modo a auxiliar na consolidação de atividades em prol da conservação do meio ambiente, em especial, dos morcegos. Sabemos que o cronograma, o planejamento das aulas e a quantidade de conteúdos abordados no ensino fundamental às vezes não permite aos professores aprofundarem muitos dos temas trabalhados.

Entretanto, os professores podem acrescentar em seus planejamentos atividades paralelas que possam ser utilizadas para melhor contemplar conteúdos que são 
essenciais para desmistificar e facilitar o entendimento da preservação das nossas espécies e por consequência dos recursos ambientais que estão sendo degradados em um ritmo bastante acelerado.

\section{REFERÊNCIAS}

BARREIRO, M. J.; ORTENCIO FILHO, H. Análise de livros didáticos sobre o tema “morcegos". Revista Ciência \& Educação, Bauru, v. 22, n. 3, p. 671-688, 2016.

BATISTA, M. V. A.; CUNHA, M. M. S.; CANDIDO, A. L. Análise do tema virologia em livros didáticos de biologia do ensino médio. Ensaio: pesquisa em educação em Ciências, v. 12, p. 145-158, 2010.

BRASIL. Ministério da Saúde. Morcegos em áreas urbanas e rurais: manual de manejo e controle. 2. ed. Brasília: Fundação Nacional de Saúde, 1998.

CAPPARROS, E. M.; MAGALHÃES JUNIOR, C. A. O. A Representação Social Sobre Morcegos Apresentada Pela Mídia Brasileira. Contexto \& Educação. Editora Unijuí Ano 30 nº 97, 2015.

CONZO JUNIOR, H. Morcegos, pernilongos, pulgas e outros sugadores de sangue.Gravuras Eduardo Ver. $1^{\circ}$ edição. Editora WMF Martins Fontes. São Paulo, 2014.

DIAS, L. S.; LEAL, A. C.; JUNIOR, C. S. EDUCAÇÃO AMBIENTAL: conceitos, metodologias e práticas. Ed. ANAP, $1^{a}$ edição. São Paulo - SP, 2016.

DRUMMOND, S. M. Morcegos: verdades e mitos. Uma análise acerca do conhecimento sobre os morcegos na sociedade: folclore, realidade e cultura.

Monografia (Graduação) - Universidade Estadual do Sudoeste da Bahia.

Departamento de Ciências Naturais, 2004.

FERREIRA, M. S.; SELLES, S. E. Análise de livros didáticos em Ciências: entre as ciências de referência e as finalidades sociais da escolarização, Educação em foco, Juiz de Fora, v.8, p. 63-78, 2004.

FOLHA PE. Pernambucano foi o primeiro caso de cura de raiva humana no

Brasil. Morador de Floresta foi mordido por um morcego em 2008, 2017. Disponível em:

<https://www.folhape.com.br/noticias/noticias/saude/2017/06/29/NWS,32794,70,613,N OTICIAS, 2190-PERNAMBUCANO-FOI-PRIMEIRO-CASO-CURA-RAIVAHUMANA-BRASIL.aspx.> Acesso em: 13/08/2019.

Recebido em: $21 / 01 / 2020$

Aceito em: 08/07/2020 
GOMES, M. C. B.; NETO, E. M. C. Morcegos: uma abordagem biológica, mitológica e etnozoológica. Editora UEFS. Feira de Santana. 2016, 135 p.

LEFEVRE, F.; LEFEVRE, A. M. C. Discurso do Sujeito Coletivo: representações sociais e intervenções comunicativas. Relato de Experiência. Florianópolis, 2014.

LIMA, I. P. Aspectos ecológicos dos quirópteros do "Campus" da Universidade

Estadual de Londrina - PR. 1994. Trabalho de Conclusão de Curso. (Bacharelado em Ciências Biológicas) - Universidade Estadual de Londrina, Londrina.

LIMA, I. P. Espécies de morcegos (Mammalia, Chiroptera) registradas em parques nas áreas urbanas do Brasil e suas implicações no uso deste ambiente. In: REIS, N. R. PERACCHI, A. L.; SANTOS, G. A. S. D. Ecologia de morcegos. Londrina: Technnical books, 2008. p. 71-85.

LIMA, J. M.; AVANZI, M. R. Professores e professoras, como podemos tratar da conservação dos morcegos? In: LAMIM-GUEDES, V.; COSTA, L. M. (orgs). Morcegos além dos mitos. São Paulo. Editora na Raiz, 2018. 165 p.

MARQUES, M. A.; ORTENCIO FILHO, H.; MAGALHÃES JUNIOR, C. A. O. Percepção de agricultores acerca da importância dos morcegos na manutenção da mata ciliar. Revista Eletrônica Mestrado Educação Ambiental. V.26, 2011.

NOVAES, R. L. M.; MENEZES-JUNIOR, L. F.; DUARTE, A. C.; FAÇANHA, A. C. Pesquisa de opinião sobre morcegos com frequentadores do Parque da prainha, Rio de Janeiro, RJ, Brasil. Revista Educação Ambiental e Ação. 26, 2008.

OLIVEIRA, F. W.; CORÁ, D. H.; BIASSI, D. L.; BALDISSERA, R.; GALIANO, D. In: LAMIM-GUEDES, V.; COSTA, L. M. (orgs). Morcegos além dos mitos. São Paulo. Editora na Raiz, 2018. 165 P.

OLIVEIRA, M. M. Como fazer pesquisa qualitativa. Petrópolis, Rio de janeiro: Editora Vozes, 7 ed. p. 232, 2016.

PACHECO, S. M.; MARQUES, R. V. Conservação de morcegos no Rio Grande do Sul. In: Freitas, T. R. O.; Vieira, E.; Pacheco, S. M. e Christoff, A. (Org.). Mamíferos Brasileiros: sistemática, genética, ecologia e conservação. Rio de Janeiro: Sociedade Brasileira de Genética. p. 91-106. 2006.

PACHECO, S, M.; SODRE, M.; GAMA, A.R.; BREDT, A.; CAVALLINI SANCHES, E. M.; MARQUES, R. V.; GUIMARAES, M. M.; BIANCONI, G. V. Morcegos urbanos: status do conhecimento e plano de ação para conservação no Brasil.

Chiroptera neotropical, v. 16, p. 629 - 647, 2010.

Recebido em: $21 / 01 / 2020$

Aceito em: 08/07/2020 
PAIVA, V. M. F. Educação ambiental: impacto na percepção e mudança de atitudes em relação aos morcegos. 2010. 54 f. Dissertação (Mestrado em Ecologia e Gestão Ambiental) - Faculdade de Ciências, Universidade de Lisboa, Lisboa, 2010. PINHEIRO, M. C.; PATRÍCIO, P. M. P.; FAMADAS, K. M.; LOURENÇO, E. C. Morcegos (Mammalia: Chiroptera) na percepção de alunos do Ensino Médio do município do Rio de Janeiro-a importância do ensino de Ciências/Biologia na conservação dos morcegos. Revista Brasileira de Extensão Universitária, vol. $9 \mathrm{n}^{\circ} 1$, 2018.

QUEIROZ, A. C. M.; SILVA, L. A. M. Morcegos Vão à Escola: Uma Análise das Informações Contidas em Livros Didáticos. In: ENCONTRO BRASILEIRO PARA O ESTUDO DE QUIRÓPTEROS, 8., 2015, Ouro Preto. Resumos... Ouro Preto: SBEQ, p. $125,2015$.

REIGOTA, M. O que é educação ambiental. Editora Brasiliense, São Paulo, Brasil, 1991, 63 p.

REIS, N. R.; PERACHI, A. L.; BATISTA, C. B.; LIMA, I. P.; PEREIRA, A. D.

História Natural dos Morcegos Brasileiros Chave de Identificação de Espécies. Rio de Janeiro, 2017. 416p.

REIS, N. R.; PERRACHI, A.L.; PEDRO, W. A.; LIMA, I.P. Morcegos do Brasil. Londrina, 2007. 253 p.

RIBEIRO, N. C. G.; MAGALHÃES JUNIOR, C. A. O. Crianças e adultos no museu: suas concepções sobre morcegos. UNOPAR CIENTÍFICA: Ciências Humanas e Educação. Londrina, v.16, n. 4, p. 263-268, 2015.

SARTIN, R. D.; MESQUITA, C. B.; SILVA, E. C.; FONSECA, F. S. R. Análise do conteúdo de botânica no livro didático e a formação de professores. IV ENEBIO e II EREBIO da REGIONAL 4. Anais... Goiana, 2012.

SCAVRONI, J.; PALEARI, L. M.; UIEDA, W. Morcegos: realidade e fantasia na concepção de crianças de área rural e urbana de Botucatu-SP. Revista Simbio-Logias. v. 1, n.2, p. 1-18, 2008.

SILVA, E. M. V. G.; SILVA, R. R.; SILVA-FILHO, T. P.; OLIVEIRA, P. J. A.; CUNHA, M. T. S.; OLIVEIRA, J. C. T.; SILVA, L. A. M. Morcegos amigos ou vilões? - A percepção dos estudantes sobre morcegos. Educação Ambiental em Ação, versão online. v. 43, p. 01, 2013.

Recebido em: 21/01/2020

Aceito em: 08/07/2020 
SILVA, J. C. R. Zoonoses e Doenças Emergentes Transmitidas por Animais Silvestres. Associação Brasileira de Veterinários de Animais Selvagens/ABRAVAS www.abravas.org.br ABRAVAS, pp. 1-4, 2004.

SILVA, L. C.; GENTILI, P. T. Importância ecossistêmica dos morcegos aos alunos da Escola Técnica Benedito Storani, município de Jundiaí-SP. Educação ambiental em ação. n.50, 2014. Disponível em: 〈http://revistaea.org/artigo.php?idartigo=1916> Acesso em 15 dezembro, 2017.

SIMMONS, N. B.; CIRRANELLO, A. L. Bat Species of theWorld: A taxonomic and geographic database. 2018. Disponível em < http://batnames.org> Acesso em 27 de Junho de 2020.

SIMÕES, T. N.; SOUZA A. Q. S.; NEVES, R. F.; ARANDAS, M. J. G. Concepções dos estudantes sobre morcegos (Chiroptera) no Município de Vitória de Santo Antão (PE). In: Congresso Brasileiro de Mastozoologia, 6., 2012, Corumbá. Resumos... Corumbá: SBMZ, p. 603. 2012.

SOARES, S.C.; RUIZ, C.M.; ROCHA, D.V.; JORGE, K. M.; SENKOWSKI, S.T.V.S.; ORTÊNCIO-FILHO, H.O.; JUNIOR, C.A.O.M. Percepção dos moradores de Goioerê PR, sobre a Fauna Silvestre Urbana. Arquivos do MUDI, v15 (1/2/3), 2011.

TADIELLO, R. B.; ROBAINA, J. V. L. Análise das percepções e discentes sobre a sequência de ensino investigativa. Revista Insignare Scientia. v.3, n.1, 2020.

UIEDA, W. História natural dos morcegos hematófagos no Brasil. In: PACHECO, S. M.; MARQUES, R. V.; ESBÉRARD, C. E. L. (Org.). Morcegos no Brasil: biologia, sistemática, ecologia e conservação. Porto Alegre: Armazém Digital, 2007. p. 179-198.

UIEDA, W. Morcegos, ecologia e saúde pública. Universidade Estadual Paulista (UNESP), 2001.

VILAR, E. M.; SILVA-FILHO, T. P.; SILVA, R. R.; GOMES, E. S.; SILVA, L. A. M. Abrigos antrópicos utilizados por morcegos no semiárido pernambucano. Boletim da Sociedade Brasileira de Mastozoologia, v. 77, p. 79-86, 2016.

VOIGT, C. C.; KINGSTON, T. Bats in the Anthropocene: conservation of bats in a changing word. Springer internation AG, cham. 2016. 
Apêndice 1: Questionário aplicado com os professores (as).

Centro Acadêmico de Vitória de Santo Antão Universidade Federal de

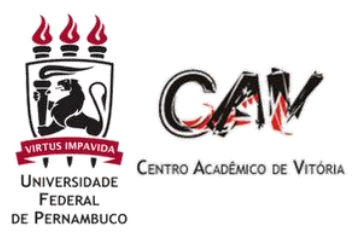

Pernambuco - CAV /UFPE

\section{QUESTIONÁRIO}

Nome:

Sexo:

Graduação:

Especialização:

Mestrado:

Doutorado:

Disciplinas que ministra: ( ) Ciências; ( ) Biologia; ( ) Outras:

Séries que trabalha: $6^{\circ}\left(\right.$ ), $7^{\circ}(), 8^{\circ}(), 9^{\circ}(\quad), 1^{\circ}$ ano ()$, 2^{\circ}$ ano ()$, 3^{\circ}$ ano () , EJA ( ).

Estimativa de alunos por ano:

Número de escolas que trabalha Quais:

Tempo de trabalho; Quais livros de ciências você utiliza para elaborar as suas aulas?

Além do livro qual outro recurso você adota na elaboração de aulas?

MORCEGO - fale quatro palavras que vêm a sua mente ao escutar esse nome.

1)Você já recebeu alguma informação sobre morcegos, onde?

2) Quais são as notícias que você lembra sobre morcegos?

3) Para você o que é um morcego?

4) Onde vivem os morcegos?

5) Conhece algum mito ou lenda sobre morcegos? Qual? Onde foi que você ouviu falar sobre isso?

6) Sobre esse mito ou lenda, qual a sua opinião?

7) Os morcegos fazem parte da fauna urbana? ( ) sim ou ( não; Por quê?

Recebido em: $21 / 01 / 2020$

Aceito em: 08/07/2020 
8) Os morcegos tem importância positiva? ( ) sim ou ( ) não; quais?

9) Os morcegos têm importância negativas? ( ) sim ou ( ) não; quais?

10) O que os morcegos comem?

11) Se você fosse dizer um número, quantas espécies de morcegos existem? No mundo; No Brasil; Em Pernambuco e no município.

12) Onde ocorrem as espécies que se alimentam de sangue (Habitat e Distribuição)?

13) Você acha importante trabalhar o tema durante as suas aulas? ( ) sim ou ( ) não; Por quê?

14) Os livros de ciências abordam o tema morcegos? ( ) sim ou ( ) não; qual assunto você lembra ter sido tratado? E em qual livro?

15) Você aborda o tema morcegos em sua aula? ( ) sim ou ( ) não; Se sim, em qual contexto você trabalha? Que assuntos são abordados?

16) Se fosse realizar alguma atividade prática com seus estudantes sobre morcegos, qual seria a atividade?

17) Você percebe algum interesse dos estudantes ao abordar o assunto?

18) Você percebe repulso ou medo dos estudantes sobre este conteúdo? Se sim, o que você faz?

19) Você tem repulso ou medo de morcegos? Por quê? 